The Harvard Kennedy School Misinformation Review1

May 2020, Volume 1, Issue 4

Attribution 4.0 International (CC BY 4.0)

Reprints and permissions: misinforeview@hks.harvard.edu

DOI: https://doi.org/10.37016/mr-2020-024

Website: misinforeview.hks.harvard.edu

\title{
Misinformation in action: Fake news exposure is linked to lower trust in media, higher trust in government when your side is in power
}

One major concern about fake news is that it could damage the public trust in democratic institutions. We examined this possibility using longitudinal survey data combined with records of online behavior.

Our study found that online misinformation was linked to lower trust in mainstream media across party lines. However, for moderates and conservatives, exposure to fake news predicted a higher confidence in political institutions. The mostly right-leaning fake news accessed by our moderate-to-conservative respondents could strengthen their trust in a Republican government. This was not true for liberals who could be biased against such content and less likely to believe its claims.

Authors: Katherine Ognyanova (1), David Lazer (2) Ronald E. Robertson (3) Christo Wilson (4)

Affiliations: (1) School of Communication \& Information, Rutgers University (2,3) Network Science Institute,

Northeastern University, (4) Khoury College of Computer Science, Northeastern University

How to cite: Ognyanova, K., Lazer, D., Robertson, R. E., \& Wilson, C. (2020). Misinformation in action: Fake news exposure is

linked to lower trust in media, higher trust in government when your side is in power. The Harvard Kennedy School (HKS)

Misinformation Review, Volume 1, Issue 4.

Received: March 26th, 2020 Accepted: May 22nd, 2020 Published: June 2nd, 2020.

\section{Research questions}

- Is exposure to fake news sources associated with lower trust in mass media?

- Is exposure to fake news sources associated with lower trust in political institutions?

\section{Essay summary}

- We collected data from U.S. respondents $(\mathrm{N}=3000)$ who participated in two survey waves conducted a month apart from each other. The surveys were sent out in late October and late November of 2018, shortly before and shortly after the U.S. midterm elections.

- Participants were also asked to install a browser extension tracking their online behavior during the time period between the surveys. About $8 \%(\mathrm{~N}=227)$ of the respondents agreed.

- The browsing history of participating respondents was used to evaluate their exposure to fake news sources and assess whether consuming misinformation was linked to changes in trust.

- We found that fake news exposure was associated with a decline in mainstream media trust among respondents.

1 A publication of the Shorenstein Center on Media, Politics and Public Policy at Harvard University's John F. Kennedy School of Government. 
- Our results also showed that fake news exposure was associated with an overall increase in political trust, and especially trust in congress and the justice system.

- Upon examining that relationship more closely, we found that fake news consumption was linked to lower political trust, but only for strong liberals. For moderates and conservatives, fake news consumption predicted higher trust in political institutions.

- Our findings confirm that the consequences of fake news cannot be examined in isolation. To effectively anticipate the implications of misinformation spread, research needs to consider the current media and political environment.

\section{Implications}

The long-standing problem of political misinformation drew public attention in the aftermath of the 2016 U.S. presidential election. Scholars, journalists, and politicians expressed alarm that the spread of fake news could destabilize political institutions and delegitimize media organizations. Despite those widespread concerns, there is relatively little research exploring the consequences of fake news consumption in the current political environment. Even though its direct electoral impact in 2016 may have been limited (Allcott \& Gentzkow, 2017), online misinformation could have other important effects on our society.

In this work, fake news is defined as fabricated information that has the format of news content but not the editorial standards and practices of legitimate journalism (Lazer et al, 2018). Consumption of fake news makes people more likely to adopt various political misperceptions (Guess et al., 2020) that can affect their subsequent behavior, including voting decisions (Weeks \& Garrett, 2014).

This work examines the potential of misinformation exposure to erode public confidence in key social institutions. We find evidence linking exposure to misinformation with trust in mainstream media and the federal government. Attitudes towards those institutions can, in turn, affect how people find and evaluate information; who they believe and how they act during exigent circumstances; as well as how they participate in the political process. Our findings thus emphasize the critical importance of technological, social, and regulatory efforts to curb the spread of fake news.

While this study has limitations, it showcases a novel approach to understanding the connection between fake news exposure and public opinion. The combination of longitudinal survey data and browser records provides a practical way to capture the complex interdependencies between individual attitudes and online behavior (see also Guess et al., 2020).

\section{Media Trust}

In recent years, mainstream news organizations have experienced a considerable decline in public confidence (Newman, Fletcher, Kalogeropoulos, Levy, \& Nielsen, 2018). The consequences of this lack of trust are especially apparent in times of crisis and uncertainty when citizens are most in need of credible sources providing current and reliable information. To the extent that fake news can undermine the public's confidence in mainstream media, it may not only leave its consumers misinformed, but also make them more vulnerable when disaster strikes.

The content of false news stories can influence our confidence in the media. Cynical coverage and tabloid-style focus on scandal can erode citizen trust in news organizations (Hopmann, Shehata, \& Stromback, 2015; Ladd, 2012). Those are characteristics typical of many fake news stories as their producers aim to increase audience engagement through sensational and divisive content. 
Fake news can also discredit the press directly by accusing them of bias, complicity, and incompetence or indirectly by contradicting a range of claims made by mainstream media. What is more, the very existence of online misinformation resembling a journalistic product can diminish the credibility of legitimate news. Confirming the relevance of those concerns, our study offers evidence that exposure to fake news is associated with a decline in the media trust of respondents.

\section{Political Trust}

The impact of fake news on political trust has important consequences for our democracy. Public confidence in political institutions affects civic and electoral behavior, with distrustful citizens more likely to sit out an election or vote for a populist candidate (Hooghe, 2018). While in some cases concerns about poor government may lead to citizen mobilization, high levels of cynicism and mistrust can cause people to withdraw from participating in politics.

Research suggests that negative or biased reporting can reduce political trust and increase cynicism and apathy (Kleinnijenhuis, van Hoof, \& Oegema, 2006). Similar considerations may apply in the case of fake news. Politically motivated fringe groups and foreign actors are said to spread misinformation mimicking the format of journalism specifically for the purpose of destabilizing democratic institutions (Wardle \& Derakhshan, 2017). Financially motivated fake news outlets produce sensational content often aiming to generate more views by appealing to partisan bias, triggering negative emotions, and fueling political arguments. Scandal and incivility in current affairs coverage can draw and hold public attention while at the same time lowering political trust (Bowler \& Karp, 2004; Mutz \& Reeves, 2005).

Based on its characteristics, many observers expect that fake news is eroding political trust. Some sources of misinformation, however, can be portrayed more accurately as working to shift trust from mainstream institutions to fringe organizations, or from one political entity to another. While a citizen decline in political trust can be harmful, an unwarranted increase in public confidence based on false stories would be similarly problematic. An unrealistically optimistic view of the government, for instance, can be dangerous if it convinces citizens that no further action or mobilization is needed.

In this work, we take steps towards unpacking the complicated relationship between consuming fabricated content and trust in political institutions. We observe that fake news is linked to a decrease in political trust among liberal respondents, but it is associated with an increase in political trust for moderates and conservatives. These findings highlight the importance of considering the current political context when examining the impact of misinformation. Whether fake news does erode public trust in political institutions is likely determined by the ideological lean of the news sources, the individuals who access them, and the current political elites running the country. Key characteristics of the content itself could also shift over time, changing its impact on public trust.

\section{Findings}

This study set out to investigate the impact of fake news consumption on confidence in democratic institutions. Combining two-wave survey data with records of online behavior, we examined the role of misinformation exposure (a binary variable) as a predictor of trust in the media and the political system. While a single fake news encounter may not affect attitudes, here we treat it as a signal that the respondent consumes at least some misinformation. It indicates that the person has visited one of the sites on our fake news list using the browser we track (see Appendix A). Given that people tend to use multiple browsers and devices, and that there are sources of misinformation we have not yet identified, it is likely that our methods underreport the actual fake news exposure of participants. 
Finding 1: Consuming misinformation was associated with a general decrease in media trust.

Fake news sources often target mainstream media organizations by accusing them of bias and incompetence. Perhaps more importantly, sensational and made-up stories that mimic the format of journalism could damage the credibility of all news content. With that in mind, journalists and scholars have expressed concerns that exposure to fabricated news would reduce people's confidence in the press. Our research found evidence confirming that assumption. Misinformation exposure during the onemonth period around the 2018 election did predict a 5\% decrease in media trust among our participants. Furthermore, consuming fake news was associated with lower mainstream media trust across all levels of political ideology.

Finding 2: Consuming misinformation was associated with a general increase in political trust.

In contrast to the negative relationship between fake news exposure and media trust, we found that consuming misinformation was associated with an increase in political trust. This link was especially strong for people's confidence in the U.S. Congress, an institution covered extensively by news media around the 2018 midterm elections. Fake news consumption was associated with a $4 \%$ increase in political trust and an $8 \%$ increase for trust in Congress.

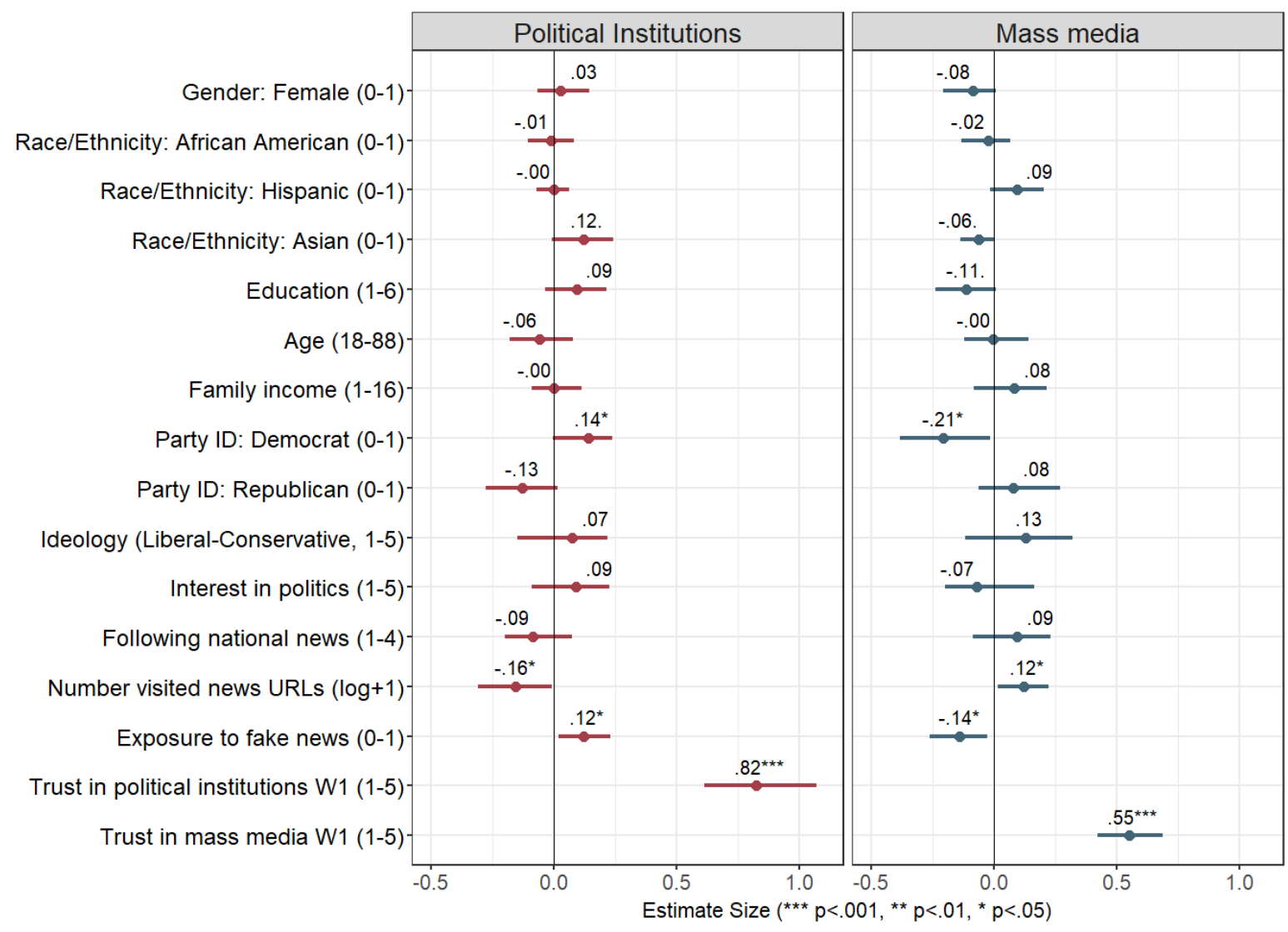

Figure 1. Trust in politics and mass media. The figure shows standardized coefficients from ordinary least squares regressions predicting political trust (on the left) and media trust (on the right). Variables whose error bars are to the right (left) of the zero line are positively (negatively) associated with the outcome. 
During our data collection, the majority of fake news sources identified by scholars and fact-checking organizations produced content with a far-right ideology (Guess, Nagler, \& Tucker, 2019). This was also reflected in our own data, as shown in Appendix $C$, which describes the fake news outlets visited by our study participants.

In late 2018, Republicans were in power in the White House, the U.S. Senate, and the House of Representatives. The Supreme Court had five justices appointed by Republican presidents and four appointed by Democrats. The recently confirmed Justice Brett Kavanaugh had just replaced the more moderate Anthony Kennedy. With all branches of government under Republican control, it may not be surprising that the predominantly right-leaning fake news content would bolster rather than erode confidence in political institutions. As demonstrated in previous research (Ceron \& Memoli, 2015), consuming pro-government content leads to increased political trust, especially among citizens who are already predisposed to be supportive of the current political institutions.

Finding 3: While the overall association between fake news consumption and political trust was positive, there were differences among ideological subgroups. Strong liberals trusted the government less after consuming fake news, while moderates and conservatives trusted it more.

Further exploration of the relationship between political trust and misinformation consumption revealed a more complicated story. For strong liberals, exposure to fabricated news was indeed linked to lower political trust. For moderates and conservatives, however, fake news consumption predicted higher trust in political institutions. This finding demonstrates that we cannot examine the effects of misinformation in isolation: its impact on citizens depends on the way in which the ideological messages present in fake news interact with the political context. In our data, strong liberals exposed to right-leaning misinformation may be most likely to reject its claims and mistrust the current Republican government. In contrast, moderate or conservative respondents may take that misinformation at face value and increase their confidence in the current political institutions.

The nature of political trust and distrust has been the subject of a long-standing debate in political science. Trust can be seen as a construct that captures our attitudes towards regimes, institutions, and policies (Miller, 1974). Alternatively, we can think of political trust as mostly reflective of our ideological agreement with the actors who govern the country at a given time (Citrin, 1974). If the former perspective holds, eroding trust could have long-term negative consequences on the way people see democratic institutions. The alternative would suggest that trust can be damaged and repaired more easily as individuals and groups transition in and out of power. Research has found some support for the latter view as people report higher levels of trust in the political system when their party is running the country (Anderson, Blais, Bowler, Donovan, \& Listhaug, 2005; Keele, 2005).

The link between political trust and ideological alignment with the governing party can further illuminate our findings. Researchers have suggested that the polarization of political trust is associated with ideologically motivated reasoning (Hetherington \& Rudolph, 2018). Motivated processing of information could lead to considerable differences in the way liberals and conservatives react to rightleaning fake news. Strong Democrats would be most motivated to evaluate right-wing content critically, distrust the source, and counter-argue messages that challenge their political beliefs. Moderates and conservatives may be more willing to overlook the problematic source and accept pro-government claims at face value. Conversely, strong Democrats would be most susceptible to any left-leaning fake news criticizing the government. Overall, motivated reasoning could result in patterns much like the ones found in this study: exposure to misinformation would be linked to a decrease in political trust for liberals and an increase for conservatives. 


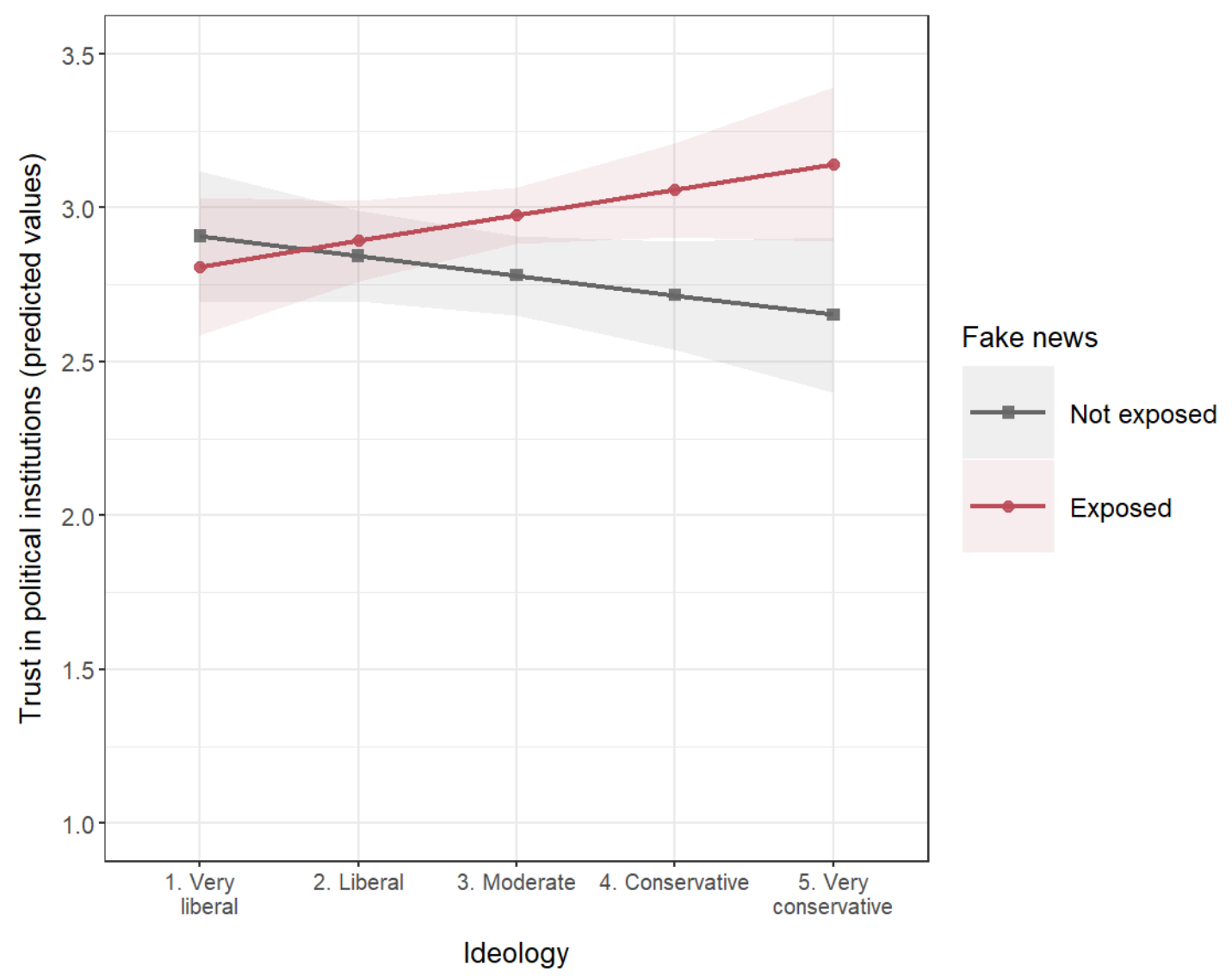

Figure 2. Interaction plot showing predicted values of trust in political institutions at different levels of ideology and fake news exposure, control variables held at mean.

As in previous research, the fake news content accessed by participants in our sample was predominantly right-leaning (see Appendix C), while the stories retrieved from legitimate sources were more balanced. The most read traditional news stories included Senate and House election coverage from the New York Times and FiveThirtyEight. The top posts from fake news sources included stories about Democrats attempting to discourage gun owners from voting; Republican Senator Ted Cruz being attacked by angry protesters at dinner; and a gay man accusing Democratic Senator Cory Booker of sexual misconduct.

While our analyses do show a link between fake news consumption and institutional trust, we cannot claim with certainty that this relationship is causal. Our results are suggestive, but unobserved confounding and reverse causality remain possible. Additional tests allow us to rule out some of the plausible alternative explanations. For instance, one might ask whether our results are specific to misinformation exposure. Would we see the same patterns when people consume other content, as long as it is similarly ideologically skewed? At least in our data, that was not the case. Consuming legitimate right-leaning news was positively associated with increased trust in the White House, but not in other political institutions. Notably, it was not linked to a decline in the media trust of participants. We conducted further tests by adding separate controls for exposure to right-wing (Fox news) and far-right (Breitbart News) content to our main models. Including those separately or together did not alter the estimates for fake news (see table B3 and B4 in Appendix B). 


\section{Methods}

\section{Data collection}

The data used in this study was collected by the opinion polling company YouGov. A total of 3,000 participants completed two surveys conducted shortly before and after the 2018 U.S. midterm elections. The first survey wave was fielded between October 18 and October 24 of 2018. The second wave was collected between November 23 and December 1 of 2018.

During the initial recruitment, survey respondents were also invited to participate in our digital data collection taking place in October and November of 2018. Individuals who consented were asked to install a browser extension compatible with Google Chrome and Firefox. This extension operated until December 1 and periodically collected the web browsing history of each participant.

The time period when we collected the digital data was characterized by considerable public attention to political news and events in the United States. On November 6, 2018, many states in the country had their first major election since Donald Trump was voted into office. In the weeks following the election, both the public and the media were focused on the results and their implications for American political life. The increased attention to political events at that time would likely strengthen the effects of exposure to mainstream and fake news content.

Out of the 3,000 respondents who completed both survey waves, a subsample of 227 (8\%) agreed to install the browser extension and participate in the digital data collection. The analyses conducted here were based on that smaller sample. While the resulting dataset includes a relatively modest number of participants, it contains a very detailed and rich record of their online behavior. Trends in the data that are prominent enough can be captured even with this relatively small sample. A sensitivity power analysis for the study models and sample size $(n=227, \alpha=.05$, power set to .80$)$ indicated that effect sizes as small as $\mathrm{f}^{2}=.04$ could be detected.

Demographic characteristics of the respondents who took part in the digital data collection are available in Appendix A, Table A1 and A2. While it was relatively diverse given its constraints, the sample underrepresented female, Black, and Hispanic U.S. residents when compared to the 2018 Census Current Population Survey. To improve the representativeness of our results, we applied post-stratification weighting for gender, race, age, education, and geographic region (Northeast, Midwest, South, or West) prior to analyzing the data.

\section{Variable measurement}

Detailed information about the way we constructed all variables used in this study, as well as tables showing their descriptive characteristics, can be found in Appendix A.

Fake news exposure was determined based on the browser history of participants. People were considered to be exposed if they had visited any of the sources in a list of domains categorized as fake news by Grinberg and colleagues (2019).

Trust in media and political institutions was measured using items adapted from the General Social Survey (GSS). Respondents were asked how much confidence they had in mass media, the White House, Congress, the Supreme Court, the military, and the justice system. To provide a more nuanced understanding of the connection between fake news exposure and trust, the analyses reported in this study were conducted separately for each of the institutions listed above, as well as for a generalized measure of political trust which combined the five items pertaining to political institutions. 
Control variables used in the analysis included gender, race and ethnicity, age, education, family income, party affiliation, political ideology, interest in politics, national news consumption, and number of visited news pages during the data collection period.

\section{Data analysis}

Prior to the analyses, we examined the item non-response levels for the two survey waves. The variables used in this study contained relatively little missing data. Missingness was $0 \%$ for the fake news exposure variable, less than $2 \%$ for the key dependent variables, and less than $5 \%$ for the control variables. The analyses were conducted using multiple imputation of the missing data.

After computing survey weights, we estimated regression models for each dependent variable measured in the second survey wave. Along with the other controls described in Appendix A, the model predictors included participant scores for the dependent variable in the first data collection wave. Controlling for pre-exposure levels of the dependent variable makes causal interpretations of its relationship with fake news consumption more plausible than they would otherwise be.

To examine the association between political trust and participant exposure to fake news sources, we estimated separate models for confidence in the White House, Congress, the Supreme Court, the military, the justice system, and the combined political trust variable (all measured on a 1-5 scale). To further explore the relationship of misinformation and institutional trust, we estimated additional models that included terms for the interaction between fake news exposure and political ideology (see Appendix B, Table B2). In the model predicting trust in political institutions, the interaction was significant and positive. The model results and interaction plot suggest that fake news exposure differs in its impact on political trust depending on the person's ideology.

\section{Bibliography}

Allcott, H., \& Gentzkow, M. (2017). Social Media and Fake News in the 2016 Election. Journal of Economic Perspectives, 31(2), 211-236. doi: 10.1257/jep.31.2.211

Anderson, C. J., Blais, A., Bowler, S., Donovan, T., \& Listhaug, O. (2005). Losers' Consent: Elections and Democratic Legitimacy. New York, NY: Oxford University Press.

Bowler, S., \& Karp, J. A. (2004). Politicians, Scandals, and Trust in Government. Political Behavior, 26(3), 271-287. doi: 10.1023/B:POBE.0000043456.87303.3a

Ceron, A., \& Memoli, V. (2015). Trust in Government and Media Slant: A Cross-Sectional Analysis of Media Effects in Twenty-Seven European Countries. The International Journal of Press/Politics, 20(3), 339359. doi: $10.1177 / 1940161215572634$

Citrin, J. (1974). Comment: The Political Relevance of Trust in Government. The American Political Science Review, 68(3), 973-988. doi: 10.2307/1959141

Egelhofer, J. L., \& Lecheler, S. (2019). Fake news as a two-dimensional phenomenon: A framework and research agenda. Annals of the International Communication Association, 43(2), 97-116. doi: 10.1080/23808985.2019.1602782

Grinberg, N., Joseph, K., Friedland, L., Swire-Thompson, B., \& Lazer, D. (2019). Fake news on Twitter during the 2016 U.S. presidential election. Science, 363(6425), 374-378. doi:

10.1126/science.aau2706 
Guess, A., Lockett, D., Lyons, B., Montgomery, J. M., Nyhan, B., \& Reifler, J. (2020). "Fake news" may have limited effects on political participation beyond increasing beliefs in false claims. Harvard Kennedy School Misinformation Review. doi: 10.37016/mr-2020-004

Guess, A., Nagler, J., \& Tucker, J. (2019). Less than you think: Prevalence and predictors of fake news dissemination on Facebook. Science Advances, 5(1), eaau4586. doi: 10.1126/sciadv.aau4586

Hetherington, M. J., \& Rudolph, T. J. (2018). Political Trust and Polarization. In E. M. Uslaner (Ed.), The Oxford Handbook of Social and Political Trust. Retrieved from http://www.oxfordhandbooks.com/view/10.1093/oxfordhb/9780190274801.001.0001/oxfordhb9780190274801-e-15

Hooghe, M. (2018). Trust and Elections. In E. M. Uslaner (Ed.), The Oxford Handbook of Social and Political Trust. Retrieved from

http://www.oxfordhandbooks.com/view/10.1093/oxfordhb/9780190274801.001.0001/oxfordhb9780190274801-e-17

Hopmann, D. N., Shehata, A., \& Stromback, J. (2015). Contagious Media Effects: How Media Use and Exposure to Game-Framed News Influence Media Trust. Mass Communication and Society, 18(6), 776-798. doi: 10.1080/15205436.2015.1022190

Keele, L. (2005). The Authorities Really Do Matter: Party Control and Trust in Government. Journal of Politics, 67(3), 873-886. doi: 10.1111/j.1468-2508.2005.00343.x

Kleinnijenhuis, J., van Hoof, A. M. J., \& Oegema, D. (2006). Negative News and the Sleeper Effect of Distrust. Harvard International Journal of Press/Politics, 11(2), 86-104. doi: 10.1177/1081180X06286417

Ladd, J. M. (2012). Why Americans Hate the Media and How It Matters. Princeton, NJ: Princeton University Press.

Lazer, D. M. J., Baum, M. A., Benkler, Y., Berinsky, A. J., Greenhill, M., Menczer, F., ... Nyhan, B. (2018). The science of fake news: Addressing fake news requires a multidisciplinary effort. Science, 4.

Miller, A. H. (1974). Political Issues and Trust in Government: 1964-1970. American Political Science Review, 68(3), 951-972. doi: 10.2307/1959140

Mutz, D. C., \& Reeves, B. (2005). The New Videomalaise: Effects of Televised Incivility on Political Trust. American Political Science Review, 99(1), 1-15. doi: 10.1017/S0003055405051452

Newman, N., Fletcher, R., Kalogeropoulos, A., Levy, D. A. L., \& Nielsen, R. K. (2018). Digital News Report 2018. Oxford, UK: Reuters Institute for the Study of Journalism.

Ognyanova, K. (2019). The Social Context of Media Trust: A Network Influence Model. Journal of Communication, 69(5), 544-567. doi: 10.1093/joc/jqz031

Wardle, C., \& Derakhshan, H. (2017). Information disorder: Toward an interdisciplinary framework for research and policymaking (p. 109). Strasbourg, France: Council of Europe.

Weeks, B. E., \& Garrett, R. K. (2014). Electoral Consequences of Political Rumors: Motivated Reasoning, Candidate Rumors, and Vote Choice during the 2008 U.S. Presidential Election. International Journal of Public Opinion Research, 26(4), 401-422. doi: 10.1093/ijpor/edu005 


\section{Funding}

This research was funded through grants by the Democracy Fund and the Hewlett Foundation.

\section{Competing interests}

None.

\section{Ethics}

Institutional review board (IRB) guidelines for human subject research were followed in the design and administration of the study. The research protocol was approved by the Internal Review Boards of Northeastern University and Rutgers University.

\section{Copyright}

This is an open access article distributed under the terms of the Creative Commons Attribution License, which permits unrestricted use, distribution, and reproduction in any medium, provided that the original author and source are properly credited.

\section{Data Availability}

The dataset used in this study, aggregated at user level, is available online in a GitHub repository at https://github.com/kateto/FakeNewsOutcomes

The raw data including detailed browser logs are not made available to protect participant privacy. 


\section{Appendix A: Measurement}

\section{FAKE NEWS EXPOSURE}

The label fake news is generally applied to intentionally deceptive digital misinformation and propaganda (Egelhofer \& Lecheler, 2019). In this work, we adopt a definition put forward by Lazer and colleagues (2018) who describe fake news as fabricated information that has the format of news content but not the editorial standards and practices of legitimate journalism. Fake news outlets are information producers willing to disregard journalistic norms in order to make profit or advance a political agenda.

In the analyses we conducted, the browsing history of participants was used to evaluate their exposure to fake news sources. The websites visited by each individual were compared to a pre-established list of sources categorized as fake news. Identifying fake news websites presents a challenge as academic consensus is yet to emerge around the best way to assess the accuracy and impartiality of online news producers. In this study, we adopted a domain classification proposed in a recent work investigating the prevalence of fake news on Twitter (Grinberg et al., 2019). In line with the definition used here, that publication defined fake news as content that adopts the format of news media, but not the intent or editorial processes needed to produce accurate content.

Grinberg et al. derived their classification of fake news domains based on evaluations by journalists, academics, and fact-checking organizations including PolitiFact, FactCheck.org, and Snopes.com. They also had human coders examine the resulting list to assess if each website on it did systematically produce falsehoods as a result of intentional fabrication or a flawed editorial process. The coding scheme and resulting domain lists are both publicly available at doi.org/10.5281/zenodo.2483311.

During the time period under observation, almost half (49\%) of the sample visited at least one website from the fake news list described above (mean $=12$ sites, median $=5$ sites). The fake news exposure variable used in the analyses was binary, with a score of 1 for exposed participants and 0 for unexposed ones. We adopted this operationalization since the total number of fake news website visits for each participant was considerably skewed and did not seem to have a simple linear or log-linear relationship with the dependent variables.

\section{TRUST IN POLITICAL INSTITUTIONS}

Following the established practice to measure political trust using items adapted from the General Social Survey (GSS), we asked participants how much confidence they had in (1) the White House, (2) Congress, (3) the Supreme Court, (4) the military, and (5) the justice system. The responses were measured on a scale ranging from 1 (None) to 5 (A great deal). Descriptives are available in Table A2.

Political trust (range 1-5, $M_{\mathrm{w} 1}=2.67, S D_{\mathrm{w}_{1}}=0.95$ and $M_{\mathrm{w} 2}=2.81, S D_{\mathrm{w} 2}=0.81$ ) was computed by averaging the five items listed above. Cronbach's alpha was acceptable ( $\left.\alpha_{\mathrm{w}_{1}}=.87, \alpha_{\mathrm{w}_{2}}=.79\right)$.

To provide a more nuanced understanding of the connection between fake news exposure and trust in political institutions, the analyses reported in this study were conducted separately for each of the five institutions listed above, as well as for the generalized measure of political trust. 


\section{MEDIA TRUST}

Media trust (range 1-5, $M_{\mathrm{w}_{1}}=2.32, S D_{\mathrm{w}_{1}}=0.87$ and $M_{\mathrm{w}_{2}}=2.33, S D_{\mathrm{w}_{2}}=0.90$ ) was also measured using an item adapted from the General Social Survey asking respondents how much confidence they had in mass media. The responses were measured on a scale ranging from 1 (None) to 5 (A great deal).

\section{CONTROL VARIABLES.}

The means and standard deviations of control variables are available in Table 1 and Table 2. Demographic controls included gender, race, and ethnicity. Models also controlled for annual family income, measured on a scale ranging from 1 (Under $\$ 10,000)$ to $16($ Over $\$ 500,000)$ and education, ranging from 1 (Less than high school) to 6 (Graduate degree). Key political controls included party affiliation (Democrat or Republican, included as binary variables); ideology ranging from 1 (Very liberal) to 5 (Very conservative); and interest in politics ranging from 1 (Not at all interested) to 5 (Extremely interested).

Two news media use variables were included as controls. One was a self-reported measure of the extent to which the respondent was following national news, ranging from 1 (Not closely at all) to 4 (Very closely).

The second news metric, number of visited news URLS, was based on the browser data collected from respondents. To identify which domains visited by the participants were non-fake news sources, we used the classification put forward by Grinberg et al. (2019). The researchers compiled a directory of news sources by generating a list of the most popular domains linked from political tweets and having each URL examined by two coders to confirm it belonged to a news organization. The total number of news sites visits by respondents ranged from 0 to $11,288(M=935, S D=1391)$. As the variable was considerably right-skewed, it was log-transformed before including it in the analysis.

Table A1. Demographic characteristics of the sample

\begin{tabular}{rccc}
\hline \multicolumn{1}{c}{ Variable } & $\begin{array}{c}\text { All } \\
\text { respondents }\end{array}$ & $\begin{array}{c}\text { Respondents } \\
\text { exposed to } \\
\text { fake news }\end{array}$ & $\begin{array}{c}\text { Respondents } \\
\text { not exposed to } \\
\text { fake news }\end{array}$ \\
\hline Exposed to fake news & $44 \%$ & $100 \%$ & $0 \%$ \\
Gender: Female & $45 \%$ & $40 \%$ & $49 \%$ \\
Gender: Male & $55 \%$ & $60 \%$ & $51 \%$ \\
Race/Ethnicity: White Non-Hispanic & $76 \%$ & $80 \%$ & $72 \%$ \\
Race/Ethnicity: African American & $8 \%$ & $6 \%$ & $10 \%$ \\
Race/Ethnicity: Hispanic & $6 \%$ & $5 \%$ & $7 \%$ \\
Race/Ethnicity: Asian & $4 \%$ & $3 \%$ & $6 \%$ \\
Party ID: Republican & $32 \%$ & $36 \%$ & $29 \%$ \\
Party ID: Democrat & $45 \%$ & $40 \%$ & $49 \%$ \\
\hline
\end{tabular}


Table A2. Key variables - descriptive statistics.

\begin{tabular}{|c|c|c|c|c|c|c|}
\hline Variable & $\begin{array}{l}\text { Mean (SD) } \\
\quad \text { W1 }\end{array}$ & $\begin{array}{c}\text { Mean (SD) } \\
\text { W2 }\end{array}$ & $\begin{array}{c}\text { Mean (SD) } \\
\text { W1 } \\
\text { Exposed } \\
\text { to fake } \\
\text { news }\end{array}$ & $\begin{array}{l}\text { Mean (SD) } \\
\text { W1 } \\
\text { Not exposed } \\
\text { to fake } \\
\text { news }\end{array}$ & $\begin{array}{l}\text { Mean (SD) } \\
\text { W2 } \\
\text { Exposed } \\
\text { to fake } \\
\text { news }\end{array}$ & $\begin{array}{l}\text { Mean (SD) } \\
\text { W2 } \\
\text { Not Exposed } \\
\text { to fake } \\
\text { news }\end{array}$ \\
\hline Age (18-88) & $47.8(16)$ & & $50.2(17)$ & $45.8(16)$ & & \\
\hline Education (1-6) & $4.2(1.5)$ & & $4.3(1.5)$ & $4.1(1.5)$ & & \\
\hline Family income (1-16) & $6.7(3.5)$ & & $6.9(3.5)$ & $6.5(3.5)$ & & \\
\hline Following national news (1-4) & $3.4(0.8)$ & & $3.6(0.7)$ & $3.3(0.8)$ & & \\
\hline Number visited news URLs (0-11.3K) & $.9 \mathrm{~K}(1.4 \mathrm{~K})$ & & $1.5 \mathrm{~K}(1.8 \mathrm{~K})$ & $.5 \mathrm{~K}(.7 \mathrm{~K})$ & & \\
\hline Ideology (Liberal-Conservative, 1-5) & $2.8(1.5)$ & & $3.0(1.5)$ & $2.7(1.4)$ & & \\
\hline Interest in politics (1-5) & $3.9(1.2)$ & $3.8(1.2)$ & $4.1(1.1)$ & $3.7(1.2)$ & $4.1(1.1)$ & $3.5(1.2)$ \\
\hline Confidence in the White House (1-5) & $2.4(1.3)$ & $2.4(1.3)$ & $2.5(1.4)$ & $2.3(1.2)$ & $2.6(1.4)$ & $2.3(1.2)$ \\
\hline Confidence in Congress (1-5) & $2.3(0.9)$ & $2.4(0.9)$ & $2.2(0.9)$ & $2.3(0.9)$ & $2.4(0.9)$ & $2.4(0.9)$ \\
\hline Confidence in the Supreme Court (1-5) & $2.7(1.1)$ & $2.9(1.0)$ & $2.8(1.1)$ & $2.6(1.1)$ & $3.0(1.1)$ & $2.9(1.0)$ \\
\hline Confidence in the military (1-5) & $3.4(1.2)$ & $3.5(1.2)$ & $3.5(1.2)$ & $3.3(1.2)$ & $3.6(1.3)$ & $3.5(1.1)$ \\
\hline Confidence in the justice system (1-5) & $2.7(0.9)$ & $2.7(0.9)$ & $2.7(0.9)$ & $2.6(0.9)$ & $2.7(0.9)$ & $2.7(0.9)$ \\
\hline Political trust (1-5) & $2.7(0.9)$ & $2.8(0.8)$ & $2.7(0.9)$ & $2.6(0.8)$ & $2.9(0.8)$ & $2.8(0.8)$ \\
\hline Media trust (1-5) & $2.3(0.9)$ & $2.3(0.9)$ & $2.5(0.9)$ & $2.2(0.8)$ & $2.5(0.9)$ & $2.2(0.8)$ \\
\hline Social media: sharing news & $2.7(1.4)$ & $2.4(1.3)$ & $2.9(1.4)$ & $2.5(1.3)$ & $2.6(1.3)$ & $2.2(1.3)$ \\
\hline Social media: comment on news & $2.7(1.2)$ & $2.6(1.3)$ & $2.9(1.2)$ & $2.5(1.2)$ & $2.8(1.3)$ & $2.4(1.3)$ \\
\hline Social media: see inaccurate news & $3.4(1.1)$ & $3.4(1.1)$ & $3.7(1.0)$ & $3.2(1.1)$ & $3.6(1.1)$ & $3.2(1.1)$ \\
\hline Social media: see fake news & $3.1(1.0)$ & $3.0(1.2)$ & $3.3(1.0)$ & $3.0(1.1)$ & $3.1(1.2)$ & $2.9(1.1)$ \\
\hline
\end{tabular}




\section{Appendix B: Results}

Table B1. Predictors of confidence in political institutions. The table includes standardized coefficients from ordinary least squares regressions with multiple imputation (MI=10).

\begin{tabular}{|c|c|c|c|c|c|}
\hline Variable & $\begin{array}{l}\text { White } \\
\text { House }\end{array}$ & $\begin{array}{l}\text { US } \\
\text { Congress }\end{array}$ & $\begin{array}{l}\text { Supreme } \\
\text { Court }\end{array}$ & Military & $\begin{array}{l}\text { Justice } \\
\text { System }\end{array}$ \\
\hline Gender: Female (0-1) & $-.06(.05)$ & $.17(.08)^{*}$ & $-.03(.07)$ & $-.03(.06)$ & $.05(.07)$ \\
\hline Race/Ethnicity: African American (0-1) & $.02(.04)$ & $.07(.09)$ & $-.01(.05)$ & $-.05(.08)$ & $-.06(.06)$ \\
\hline Race/Ethnicity: Hispanic (0-1) & $.02(.03)$ & $-.08(.04)$ & $.04(.05)$ & $.01(.05)$ & $-.01(.05)$ \\
\hline Race/Ethnicity: Asian (0-1) & $.09(.04) *$ & $.20(.05)^{* * *}$ & $.04(.09)$ & $.14(.04)^{* * *}$ & $.01(.08)$ \\
\hline Age (18-88) & $-.00(.05)$ & $.04(.09)$ & $.06(.07)$ & $.09(.07)$ & $.19(.08)^{*}$ \\
\hline Education (1-6) & $-.09(.05)$ & $-.00(.08)$ & $.04(.06)$ & $-.08(.06)$ & $-.06(.07)$ \\
\hline Family income (1-16) & $-.03(.05)$ & $.02(.09)$ & $-.01(.07)$ & $.03(.07)$ & $-.00(.09)$ \\
\hline Party ID: Democrat (0-1) & $.02(.06)$ & $.16(.10)$ & $.14(.08)$ & $.08(.08)$ & $.12(.09)$ \\
\hline Party ID: Republican (0-1) & $-.13(.08)$ & $-.15(.10)$ & $-.08(.10)$ & $-.02(.08)$ & $.06(.10)$ \\
\hline Ideology (Liberal-Conservative, 1-5) & $.07(.08)$ & $.03(.11)$ & $.12(.11)$ & $.10(.11)$ & $-.01(.14)$ \\
\hline Interest in politics (1-5) & $.05(.06)$ & $.10(.11)$ & $.12(.09)$ & $.02(.08)$ & $.07(.11)$ \\
\hline Following national news (1-4) & $-.05(.05)$ & $-.05(.10)$ & $-.12(.08)$ & $-.04(.09)$ & $-.00(.09)$ \\
\hline Number visited news URLs $(\log +1)$ & $-.06(.05)$ & $-.20(.07)^{* *}$ & $-.17(.09)^{*}$ & $-.07(.07)$ & $-.16(.08)^{*}$ \\
\hline Exposed to fake news (0-1) & $-.01(.05)$ & $.23(.07)^{* * *}$ & .14 (.07) & $-.04(.06)$ & $.19(.08)^{*}$ \\
\hline Confidence in the White House in W1 (1-5) & $.89(.09)^{* * *}$ & - & - & - & - \\
\hline Confidence in Congress in W1 (1-5) & - & $.57(.08)^{* * *}$ & - & - & - \\
\hline Confidence in the Supreme Court in W1 (1- & - & - & $.63(.09)^{* * *}$ & - & - \\
\hline Confidence in the military in W1 (1-5) & - & - & - & $.68(.08)^{* * *}$ & - \\
\hline Confidence in the justice system in W1 (1-5) & - & - & - & - & $.55(.09)^{* * *}$ \\
\hline Observations & 227 & 227 & 227 & 227 & 227 \\
\hline$R^{2}$ & .78 & .42 & .47 & .61 & .41 \\
\hline$\Delta R^{2}$ Fake news exposure & .00 & .04 & .02 & .00 & .03 \\
\hline
\end{tabular}

Estimate Size $(* * * p<.001, * * p<.01, * p<.05, . p<0.1)$ 
Table B2. Predictors political and media trust. The table includes standardized coefficients from ordinary least squares regressions with multiple imputation $(\mathrm{MI}=10)$.

\begin{tabular}{|c|c|c|c|c|}
\hline Variable & $\begin{array}{c}\text { Political } \\
\text { trust }\end{array}$ & $\begin{array}{c}\text { Media } \\
\text { trust }\end{array}$ & $\begin{array}{c}\text { Political } \\
\text { trust }\end{array}$ & $\begin{array}{c}\text { Media } \\
\text { trust }\end{array}$ \\
\hline Gender: Female (0-1) & $.03(.05)$ & $-.08(.06)$ & $.04(.06)$ & $-.09(.06)$ \\
\hline Race/Ethnicity: African American (0-1) & $-.01(.05)$ & $-.02(.06)$ & $-.02(.05)$ & $-.02(.06)$ \\
\hline Race/Ethnicity: Hispanic (0-1) & $-.00(.03)$ & $.09(.06)$ & $.01(.03)$ & $.09(.06)$ \\
\hline Race/Ethnicity: Asian (0-1) & $.12(.06)$ & $-.06(.04)$ & $.12(.06)^{*}$ & $-.06(.04)$ \\
\hline Age (18-88) & $.09(.06)$ & $-.11(.07)$ & $.10(.06)$ & $-.12(.07)$ \\
\hline Education (1-6) & $-.06(.07)$ & $-.00(.07)$ & $-.05(.07)$ & $-.00(.07)$ \\
\hline Family income (1-16) & $-.00(.05)$ & $.08(.07)$ & $.01(.05)$ & $.08(.07)$ \\
\hline Party ID: Democrat (0-1) & $.14(.07)^{*}$ & $-.21(.10)^{*}$ & $.13(.07)^{*}$ & $-.21(.10)^{*}$ \\
\hline Party ID: Republican (0-1) & $-.13(.08)$ & $.08(.08)$ & $-.12(.08)$ & $.08(.09)$ \\
\hline Ideology (Liberal-Conservative, 1-5) & $.07(.10)$ & $.13(.11)$ & $.07(.09)$ & $.13(.11)$ \\
\hline Interest in politics (1-5) & $.09(.08)$ & $-.07(.09)$ & $.08(.08)$ & $-.07(.09)$ \\
\hline Following national news (1-4) & $-.09(.07)$ & $.09(.08)$ & $-.08(.07)$ & $.09(.08)$ \\
\hline Number visited news URLs $(\log +1)$ & $-.16(.07)^{*}$ & $.12(.05)^{*}$ & $-.15(.07)^{*}$ & $.12(.05)^{*}$ \\
\hline Exposed to fake news (0-1) & $.12(.05)^{*}$ & $-.14(.06)^{*}$ & $.11(.05)^{*}$ & $-.14(.06)^{*}$ \\
\hline Political trust in W1 (1-5) & $.82(.11)^{* * *}$ & - & $.82(.11)^{* * *}$ & - \\
\hline Media trust in W1 (1-5) & - & $.55(.07)^{* * *}$ & - & $.55(.07)^{* * *}$ \\
\hline Ideology x Fake news exposure & - & - & $.11(.05)^{*}$ & $-.02(.06)$ \\
\hline Observations & 227 & 227 & 227 & 227 \\
\hline $\mathrm{R}^{2}$ & .69 & .63 & .71 & .63 \\
\hline$\Delta R^{2}$ Fake news exposure & .02 & .01 & .02 & .01 \\
\hline
\end{tabular}

Estimate Size $(* * * p<.001, * * p<.01, * p<.05, . p<0.1)$ 
Table B3. Predictors of confidence in political institutions. The table includes standardized coefficients from ordinary least squares regressions with multiple imputation (MI=10).

\begin{tabular}{|c|c|c|c|c|c|}
\hline Variable & $\begin{array}{l}\text { White } \\
\text { House }\end{array}$ & $\begin{array}{c}\text { US } \\
\text { Congress }\end{array}$ & $\begin{array}{l}\text { Supreme } \\
\text { Court }\end{array}$ & Military & $\begin{array}{l}\text { Justice } \\
\text { System }\end{array}$ \\
\hline Gender: Female (0-1) & $-.05(.05)$ & $.17(.08) *$ & $-.01(.07)$ & $.00(.06)$ & $.05(.07)$ \\
\hline Race/Ethnicity: African American (0-1) & $.03(.04)$ & $.06(.09)$ & $-.02(.05)$ & $-.04(.08)$ & $-.06(.06)$ \\
\hline Race/Ethnicity: Hispanic (0-1) & $.02(.03)$ & $-.07(.04)$ & $.05(.05)$ & $.00(.05)$ & $-.00(.05)$ \\
\hline Race/Ethnicity: Asian (0-1) & $.08(.05)$ & $.21(.06)^{* * *}$ & $.04(.09)$ & $.13(.03)^{* * *}$ & $.00(.08)$ \\
\hline Age (18-88) & $-.02(.05)$ & $.04(.09)$ & $.07(.07)$ & $.08(.07)$ & $.19(.08) *$ \\
\hline Education (1-6) & $-.09(.06)$ & $.02(.08)$ & $.05(.07)$ & $-.08(.06)$ & $-.05(.07)$ \\
\hline Family income (1-16) & $-.03(.05)$ & $.01(.08)$ & $-.02(.07)$ & $.06(.07)$ & $-.04(.08)$ \\
\hline Party ID: Democrat (0-1) & $.04(.06)$ & $.18(.11)$ & $.12(.09)$ & .08 (.09) & $.13(.09)$ \\
\hline Party ID: Republican (0-1) & $-.08(.07)$ & $-.14(.11)$ & $-.08(.11)$ & $-.03(.08)$ & $.06(.10)$ \\
\hline Ideology (Liberal-Conservative, 1-5) & $.08(.08)$ & $.06(.12)$ & $.13(.12)$ & $.09(.12)$ & $.01(.14)$ \\
\hline Interest in politics (1-5) & $.05(.06)$ & $.11(.11)$ & $.12(.10)$ & $.02(.08)$ & $.09(.11)$ \\
\hline Following national news (1-4) & $-.04(.06)$ & $-.03(.10)$ & $-.09(.09)$ & $-.06(.09)$ & $.01(.09)$ \\
\hline Number visited news URLs $(\log +1)$ & $-.14(.06)^{*}$ & $-.18(.08)^{*}$ & $-.15(.08)$ & $-.13(.08)$ & $-.18(.09)^{*}$ \\
\hline Exposed to Fox News (0-1) & $.13(.05)^{*}$ & $-.07(.08)$ & $.02(.07)$ & $.13(.10)$ & $.14(.08)$ \\
\hline Exposed to Breitbart (0-1) & $.08(.04)$ & $.01(.07)$ & $-.12(.10)$ & $.09(.05)$ & $-.09(.09)$ \\
\hline Exposed to fake news (0-1) & $-.01(.04)$ & $.24(.07)^{* * *}$ & $.15(.07)^{*}$ & $-.05(.06)$ & $.17(.08)^{*}$ \\
\hline Confidence in the White House in W1 (1-5) & $.81(.09) * * *$ & - & - & - & - \\
\hline Confidence in Congress in W1 (1-5) & - & $.55(.08) * * *$ & - & - & - \\
\hline Confidence in the Supreme Court in W1 (1-5) & - & - & $.61(.10)^{* * *}$ & - & - \\
\hline Confidence in the military in W1 (1-5) & - & - & - & $.64(.08)^{* * *}$ & - \\
\hline Confidence in the justice system in W1 (1-5) & - & - & - & - & $.51(.09)^{* * *}$ \\
\hline Observations & 227 & 227 & 227 & 227 & 227 \\
\hline $\mathrm{R}^{2}$ & .78 & .42 & .47 & .61 & .41 \\
\hline
\end{tabular}

Estimate Size $\left(* * * p<.001,{ }^{* *} p<.01, * p<.05, . p<0.1\right)$ 
Table B4. Predictors political and media trust. The table includes standardized coefficients from ordinary least squares regressions with multiple imputation ( $M I=10)$.

\begin{tabular}{|c|c|c|}
\hline Variable & $\begin{array}{c}\text { Political } \\
\text { trust }\end{array}$ & $\begin{array}{c}\text { Media } \\
\text { trust }\end{array}$ \\
\hline Gender: Female (0-1) & $.05(.05)$ & $-.09(.06)$ \\
\hline Race/Ethnicity: African American (0-1) & $-.01(.05)$ & $-.02(.06)$ \\
\hline Race/Ethnicity: Hispanic (0-1) & $-.00(.03)$ & $.09(.06)$ \\
\hline Race/Ethnicity: Asian (0-1) & $.12(.06)$ & $-.07(.04)$ \\
\hline Age (18-88) & $.09(.07)$ & $-.12(.07)$ \\
\hline Education (1-6) & $-.05(.06)$ & $-.00(.07)$ \\
\hline Family income (1-16) & $-.00(.06)$ & $.08(.07)$ \\
\hline Party ID: Democrat (0-1) & $.14(.08)$ & $-.21(.10)^{*}$ \\
\hline Party ID: Republican (0-1) & $-.11(.09)$ & .09 ( .09) \\
\hline Ideology (Liberal-Conservative, 1-5) & $.09(.11)$ & $.12(.11)$ \\
\hline Interest in politics (1-5) & .10 (.09) & $-.06(.11)$ \\
\hline Following national news (1-4) & $-.08(.08)$ & .09 ( .09) \\
\hline Number visited news URLs $(\log +1)$ & $-.19(.08)^{*}$ & $.11(.06)$ \\
\hline Exposed to Fox News (0-1) & $.08(.06)$ & $.05(.06)$ \\
\hline Exposed to Beritbart (0-1) & $.01(.06)$ & $-.02(.06)$ \\
\hline Exposed to fake news (0-1) & $.12(.06)^{*}$ & $-.15(.06)^{*}$ \\
\hline Political trust in W1 (1-5) & $.78(.12)^{* * *}$ & - \\
\hline Media trust in W1 (1-5) & - & $.55(.07)^{* * *}$ \\
\hline Observations & 227 & 227 \\
\hline $\mathrm{R}^{2}$ & .69 & .63 \\
\hline
\end{tabular}




\section{Appendix C: Fake news}

Table C1. Fake news domains visited by users in the data. List of fake websites and bias scores

\begin{tabular}{|c|c|c|c|c|}
\hline $\begin{array}{r}\text { Fake news } \\
\text { domains }\end{array}$ & $\begin{array}{c}\text { Bias score } \\
\text { [Range }-1 \text { to } 1] \\
\text { Dem }<0<\text { Rep }\end{array}$ & $\begin{array}{c}\text { Democrats } \\
\text { (percent who } \\
\text { visited the site) }\end{array}$ & $\begin{array}{c}\text { Republicans } \\
\text { (percent who } \\
\text { visited the site) }\end{array}$ & $\begin{array}{l}\text { Total users } \\
\text { (percent who } \\
\text { visited the site) }\end{array}$ \\
\hline powderedwigsociety.com & 0.972 & $0.00 \%$ & $1.40 \%$ & $0.40 \%$ \\
\hline ilovemyfreedom.org & 0.926 & $0.00 \%$ & $8.20 \%$ & $3.10 \%$ \\
\hline eaglerising.com & 0.921 & $0.00 \%$ & $2.70 \%$ & $0.90 \%$ \\
\hline louderwithcrowder.com & 0.915 & $1.00 \%$ & $2.70 \%$ & $1.30 \%$ \\
\hline en-volve.com & 0.902 & $0.00 \%$ & $1.40 \%$ & $0.40 \%$ \\
\hline thefederalistpapers.org & 0.899 & $1.00 \%$ & $2.70 \%$ & $2.60 \%$ \\
\hline conservativefiringline.com & 0.896 & $0.00 \%$ & $1.40 \%$ & $0.40 \%$ \\
\hline theconservativetreehouse.com & 0.891 & $0.00 \%$ & $4.10 \%$ & $1.30 \%$ \\
\hline conservativedailypost.com & 0.889 & $0.00 \%$ & $1.40 \%$ & $0.40 \%$ \\
\hline bb4sp.com & 0.889 & $0.00 \%$ & $1.40 \%$ & $0.40 \%$ \\
\hline 100percentfedup.com & 0.888 & $0.00 \%$ & $1.40 \%$ & $1.30 \%$ \\
\hline uschronicle.com & 0.888 & $0.00 \%$ & $2.70 \%$ & $0.90 \%$ \\
\hline afa.net & 0.884 & $0.00 \%$ & $1.40 \%$ & $0.90 \%$ \\
\hline clashdaily.com & 0.878 & $0.00 \%$ & $0.00 \%$ & $0.40 \%$ \\
\hline barenakedislam.com & 0.875 & $0.00 \%$ & $1.40 \%$ & $0.40 \%$ \\
\hline wnd.com & 0.870 & $1.00 \%$ & $9.60 \%$ & $4.40 \%$ \\
\hline thehornnews.com & 0.868 & $0.00 \%$ & $4.10 \%$ & $1.30 \%$ \\
\hline dennismichaellynch.com & 0.867 & $0.00 \%$ & $2.70 \%$ & $0.90 \%$ \\
\hline rightwingnews.com & 0.865 & $0.00 \%$ & $0.00 \%$ & $0.40 \%$ \\
\hline judicialwatch.org & 0.864 & $0.00 \%$ & $9.60 \%$ & $4.40 \%$ \\
\hline thegatewaypundit.com & 0.864 & $1.00 \%$ & $11.00 \%$ & $5.70 \%$ \\
\hline dailywire.com & 0.850 & $4.90 \%$ & $17.80 \%$ & $11.00 \%$ \\
\hline nowtheendbegins.com & 0.844 & $0.00 \%$ & $2.70 \%$ & $0.90 \%$ \\
\hline frontpagemag.com & 0.836 & $1.00 \%$ & $4.10 \%$ & $2.20 \%$ \\
\hline tmn.today & 0.833 & $0.00 \%$ & $5.50 \%$ & $2.60 \%$ \\
\hline dcclothesline.com & 0.828 & $0.00 \%$ & $2.70 \%$ & $0.90 \%$ \\
\hline fellowshipoftheminds.com & 0.825 & $0.00 \%$ & $2.70 \%$ & $0.90 \%$ \\
\hline endtimeheadlines.org & 0.807 & $0.00 \%$ & $2.70 \%$ & $1.30 \%$ \\
\hline
\end{tabular}




\begin{tabular}{|c|c|c|c|c|}
\hline madworldnews.com & 0.805 & $0.00 \%$ & $4.10 \%$ & $1.80 \%$ \\
\hline tribunist.com & 0.799 & $1.00 \%$ & $0.00 \%$ & $0.90 \%$ \\
\hline infowars.com & 0.782 & $0.00 \%$ & $5.50 \%$ & $2.60 \%$ \\
\hline endoftheamericandream.com & 0.729 & $0.00 \%$ & $1.40 \%$ & $0.40 \%$ \\
\hline yournewswire.com & 0.704 & $2.00 \%$ & $1.40 \%$ & $1.30 \%$ \\
\hline dailycaller.com & 0.696 & $4.90 \%$ & $27.40 \%$ & $13.70 \%$ \\
\hline beforeitsnews.com & 0.679 & $0.00 \%$ & $2.70 \%$ & $1.30 \%$ \\
\hline zerohedge.com & 0.677 & $1.00 \%$ & $13.70 \%$ & $5.70 \%$ \\
\hline anonews.co & 0.527 & $2.00 \%$ & $4.10 \%$ & $3.10 \%$ \\
\hline neonnettle.com & 0.506 & $0.00 \%$ & $4.10 \%$ & $1.30 \%$ \\
\hline express.co.uk & 0.442 & $19.60 \%$ & $15.10 \%$ & $19.40 \%$ \\
\hline disclose.tv & 0.365 & $0.00 \%$ & $1.40 \%$ & $0.40 \%$ \\
\hline naturalnews.com & 0.360 & $0.00 \%$ & $4.10 \%$ & $1.80 \%$ \\
\hline empirenews.net & 0.314 & $0.00 \%$ & $0.00 \%$ & $0.40 \%$ \\
\hline worldnewsdailyreport.com & 0.195 & $2.90 \%$ & $1.40 \%$ & $1.80 \%$ \\
\hline awarenessact.com & 0.126 & $2.00 \%$ & $0.00 \%$ & $1.30 \%$ \\
\hline davidwolfe.com & 0.124 & $0.00 \%$ & $1.40 \%$ & $0.40 \%$ \\
\hline huzlers.com & 0.070 & $2.00 \%$ & $0.00 \%$ & $0.90 \%$ \\
\hline anonhq.com & 0.061 & $0.00 \%$ & $0.00 \%$ & $0.40 \%$ \\
\hline inquisitr.com & 0.036 & $12.70 \%$ & $4.10 \%$ & $10.60 \%$ \\
\hline en.mediamass.net & 0.031 & $1.00 \%$ & $1.40 \%$ & $1.80 \%$ \\
\hline collective-evolution.com & 0.007 & $1.00 \%$ & $1.40 \%$ & $0.90 \%$ \\
\hline theeventchronicle.com & 0.000 & $1.00 \%$ & $2.70 \%$ & $1.30 \%$ \\
\hline themindunleashed.com & 0.000 & $2.00 \%$ & $1.40 \%$ & $1.80 \%$ \\
\hline iotwreport.com & 0.000 & $1.00 \%$ & $2.70 \%$ & $1.30 \%$ \\
\hline friendsofsyria.wordpress.com & 0.000 & $0.00 \%$ & $1.40 \%$ & $0.40 \%$ \\
\hline concealednation.org & 0.000 & $0.00 \%$ & $2.70 \%$ & $0.90 \%$ \\
\hline democraticmoms.com & 0.000 & $1.00 \%$ & $0.00 \%$ & $0.40 \%$ \\
\hline dailyheadlines.net & 0.000 & $0.00 \%$ & $2.70 \%$ & $0.90 \%$ \\
\hline bizstandardnews.com & 0.000 & $2.00 \%$ & $0.00 \%$ & $0.90 \%$ \\
\hline 2ndvote.com & 0.000 & $0.00 \%$ & $1.40 \%$ & $0.40 \%$ \\
\hline ahtribune.com & 0.000 & $0.00 \%$ & $1.40 \%$ & $0.40 \%$ \\
\hline crooksandliars.com & -0.701 & $3.90 \%$ & $0.00 \%$ & $2.60 \%$ \\
\hline palmerreport.com & -0.733 & $5.90 \%$ & $0.00 \%$ & $3.10 \%$ \\
\hline bipartisanreport.com & -0.747 & $2.00 \%$ & $0.00 \%$ & $0.90 \%$ \\
\hline
\end{tabular}

